\title{
Risk factors and consequences of undiagnosed cesarean scar pregnancy: a cohort study in China
}

\author{
Ri-hua Xie ${ }^{1}$, Xiaoyan Guo ${ }^{2}$, Meng Li ${ }^{3}$, Yan Liao ${ }^{4,5}$, Laura Gaudet ${ }^{4,5}$, Mark Walker ${ }^{4,5,6,7}$, Huizhong Lei ${ }^{2^{*}}$ and
} Shi Wu Wen ${ }^{4,5,7^{*}}$ (D)

\begin{abstract}
Background: The historically high cesarean section rate and the recent change in second-child policy could increase the risk of cesarean scar pregnancy (CSP) in China. This study aims to assess risk factors and consequences of undiagnosed CSP in China.

Methods: We conducted a retrospective cohort study between January 2013 and December 2017 in Qingyuan, Guangdong, China. Independent risk factors for undiagnosed CSP at the first contact with healthcare providers were assessed by log binomial regression analysis. Occurrence of serious complications was compared between undiagnosed and diagnosed CSP cases.

Results: A total of 195 women with CSP were included in the analysis. Of them, 81 (41.5\%) women were undiagnosed at the first contact with healthcare providers. Women initially cared in primary or secondary hospitals were at increased risk for undiagnosed CSP: adjusted relative risks $(95 \%$ confidence intervals) were $3.28(2.06,5.22)$ and $1.91(1.16,3.13)$, respectively, compared with women initially cared in the tertiary hospital. Undiagnosed CSP cases had higher incidences in serious complications (11 versus 0 ) and post-surgery anemia (23 (28.4\%) versus 8 (7.0\%)), stayed longer in hospital, and cost higher than diagnosed CSP cases.
\end{abstract}

Conclusions: Initial care provided at primary or secondary maternity care facilities is an important risk factor for undiagnosed CSP, with serious consequences to the affected women.

Keywords: Cesarean scar pregnancy, Undiagnosed, Risk factors, Adverse outcomes

\section{Background}

Cesarean scar pregnancy (CSP) is a special type of ectopic pregnancy, in which the fertilized egg and trophoblast cells are implanted after cesarean section [1-4]. The incidence of CSP varies greatly from $1 / 1800$ to $1 /$ 7500 pregnancies [4-6]. This is related to the high cesarean section rate in the past decades [2]. The recent relaxation of the second-child policy might increase additional risk of CSP in reproductive age women with a history of cesarean section in China [7].

* Correspondence: Ihz3811@163.com; swwen@ohri.ca

${ }^{2}$ Department of Obstetrics and Gynecology, the Sixth Affiliated Hospital of

Guangzhou Medical University, Qingyuan, Guangdong, China

${ }^{4}$ Ottawa Hospital Research Institute, Ottawa, ON, Canada

Full list of author information is available at the end of the article
Clinical symptoms of CSP are not typical, thus, diagnosing accurately based on irregular menstrual period, vaginal bleeding, and urine human chorionic gonadotropin (HCG) positive alone is difficult. If CSP is not diagnosed timely, the pregnancy will continue and lead to serious complications such as placenta accreta, placenta previa, uterine rupture, and heavy bleeding during surgery $[1,3,4]$. With a combination of cesarean section history and accurate ultrasound and/or MRI examination, a timely and correct diagnosis can reduce occurrence of these complications $[1,3,4]$.

Most previous studies on CSP were case reports or case series with no formal assessment of risk factors for undiagnosed CSP $[1,5,6,8-21]$. Therefore, the present retrospective cohort study aims to explore the risk factors of undiagnosed CSP at the first contact with

(c) The Author(s). 2019 Open Access This article is distributed under the terms of the Creative Commons Attribution 4.0 International License (http://creativecommons.org/licenses/by/4.0/), which permits unrestricted use, distribution, and reproduction in any medium, provided you give appropriate credit to the original author(s) and the source, provide a link to the Creative Commons license, and indicate if changes were made. The Creative Commons Public Domain Dedication waiver (http://creativecommons.org/publicdomain/zero/1.0/) applies to the data made available in this article, unless otherwise stated. 
healthcare providers and to assess adverse outcomes of undiagnosed CSP cases.

\section{Methods}

\section{Study design and study setting}

In this cohort study, we used data collected for routine quality assurance purposes, thus, the Research Ethics Board of The Sixth Affiliated Hospital of Guangzhou Medical University concluded that an ethical approval was not required and no consent from patients was needed.

The study was conducted in Qingyuan region that is a prefecture-level region in northern part of Guangdong province in China [22]. There are 91 qualified primary maternity care facilities and 15 qualified secondary maternity care facilities. The primary care facilities are mostly township hospitals with 1-2 attending physicians who had general medical training and the secondary care facilities are mostly county hospitals with $3-4$ attending physicians who had some specialized training in maternity care. There are general ultrasound machines in both township and county hospitals. However, there are no obstetric specific ultrasound machines in these hospitals. Only non-complicated surgeries such as therapeutic abortion and elective cesarean section can be performed in these two-level hospitals. The Sixth Affiliated Hospital of Guangzhou Medical University, where data on CSP cases for this study were collected, is the only tertiary care hospital in the region, with an experienced maternity care team. In 2017, 18 attending physicians in this team had complete specialty training in maternity care. This maternity care team is also provided with facilities for diagnosis and treatment of high-risk pregnancy, including monitors, $4 \mathrm{D}$ ultrasound machines, color ultrasound machines, transvaginal ultrasound machines, and supported by hospital's anesthesia, surgery, and intensive care teams. Although all three levels of maternity care facilities in Qingyuan provide healthcare to low-risk pregnancies, women with an elevated risk are referred to higher level of hospitals, depending on clinical conditions, either to secondary hospitals (middle risk) or to the tertiary hospital (high risk). For high-risk pregnancies with no emergency, the referral time is normally 4 to 7 days, and for the high-risk pregnancies with emergency, it is 0.5 to $4 \mathrm{~h}$ (depending on the distance and the means of transportation). All CSP women were referred to the tertiary hospital, and few CSP women in the region sought treatment outside (for example, in 2017 official records, no CSP case was treated in any hospital outside of Qingyuan).

\section{Study sample}

All CSP cases in Qingyuan from January 2013 to December 2017 were included in this study. Demographic and clinical data were retrieved from the medical charts by trained personnel.

\section{Outcome measures}

The primary outcome of this study was undiagnosed CSP at the first contact with healthcare providers. All CSP cases were eventually diagnosed accurately at the tertiary hospital using data from multiple sources, including history of cesarean section, clinical manifestation, ultrasound scan, Doppler probe, and postoperative pathological examination. However, many CSP cases were undiagnosed at the first contact with healthcare providers.

Secondary outcomes included serious post-surgical complications, post-surgical anemia, length of hospital stay, and hospital cost. Serious complications in this study included placenta accreta, placenta previa, uterine rupture, heavy bleeding during surgery, and "near miss". Placenta accrete, placenta previa, and uterine rupture were based on clinical diagnosis, and heavy bleeding during surgery was recorded by on-duty attending physicians according to their judgement of the patient's condition. "Near miss" is a serious adverse event that a pregnant woman comes close to death, but from which she survives. Post-surgical anemia is defined as hemoglobin level of 6-9 g/100 ml.

\section{Risk factors of undiagnosed CSP}

Risk factors included maternal age, parity, rural resident, gestational age, and type of health care facility at the first contact with healthcare providers.

\section{Statistical analysis}

We first described baseline characteristics of study participants. We then analyzed risk factors of undiagnosed CSP. A log binomial model was used to estimate independent effect of risk factors, with undiagnosed CSP as outcome measure, and relative risk (RR) and 95\% confidence interval $(\mathrm{CI})$ as effect measure. Full model with all risk factors included in the regression analysis was performed. There were two levels of independent variables: the type of health care facilities measured at the hospital level and the remaining variables measured at the patient level. We thus used multi-level model to run log binomial regression. We also compared secondary outcomes between undiagnosed CSP cases and diagnosed CSP cases at the first contact with healthcare providers. Chi-square test was used to compare categorical outcomes and t-test was used to compare continuously distributed outcomes. Finally, we explored the main reasons for undiagnosed CSP at the first contact of healthcare providers. 


\section{Results}

Occurrence of undiagnosed CSP at the first contact with healthcare providers

There were 324,335 births in Qingyuan during the study period, of them, 195 CSP cases were identified, yielding a rate of 60 CSP cases per 100,000 births. Of the 195 CSP cases, 81 (41.5\%) were undiagnosed at the first contact with healthcare providers.

\section{Characteristics of CSP cases}

Table 1 shows characteristics of CSP cases. Average age of these women was 32 years and average timing of the first contact with healthcare providers was 7.6 gestational weeks, with $>60 \%$ of them initially seeking care at primary (level 1) or secondary (level 2) health care facilities (Table 1).

\section{Risk factors of undiagnosed CSP at the first contact with healthcare providers}

Table 2 presents risk factors of undiagnosed CSP at initial contact with a healthcare provider. Initial care provided at primary and secondary health care facilities was the only independent risk factor, which was significantly associated with an increased risk of undiagnosed CSP. Compared with those patients initially cared at the tertiary hospital, adjusted RRs (95\% CIs) were 3.28 (2.06, $5.22)$ and $1.91(1.16,3.13)$, respectively, for those who were initially cared at primary and secondary health care

Table 1 Characteristics of CSP cases, Qingyuan, Guangdong, China, 2013 to 2017

\begin{tabular}{|c|c|}
\hline Characteristics & \\
\hline Age in year, Mean+_SD, Medium, (range) & $\begin{array}{l}31.9 \pm 5.4,32 \\
19-44\end{array}$ \\
\hline \multicolumn{2}{|l|}{ Parity $(n, \%)$} \\
\hline 1 & $106(54.36)$ \\
\hline$>=2$ & $89(45.64)$ \\
\hline \multicolumn{2}{|l|}{ Rural residence $(n, \%)$} \\
\hline Yes & $120(61.540029$ \\
\hline No & $75(38.46)$ \\
\hline $\begin{array}{l}\text { Gestational age at the first contact with healthcare } \\
\text { provider, s, MeanSD, Medium, (range) }\end{array}$ & $\begin{array}{l}7.6 \pm 2.2,7.1 \\
(4.57,21.7)\end{array}$ \\
\hline \multicolumn{2}{|l|}{ Type of initial health care $(n, \%)$} \\
\hline Primary $^{a}$ & $56(28.72)$ \\
\hline Secondary & $61(32.28)$ \\
\hline Tertiary & $78(40.00)$ \\
\hline \multicolumn{2}{|l|}{ Undiagnosed CSP (n, \%) } \\
\hline Yes & $81(41.54)$ \\
\hline No & $114(58.46)$ \\
\hline
\end{tabular}

ancluding one patient self-treated using medications, without seeking care from any healthcare provider facilities. No statistically significant association with undiagnosed CSP was observed in other risk factors (Table 2).

\section{Comparison of secondary outcomes between undiagnosed and diagnosed CSP cases}

Table 3 shows outcomes between undiagnosed and diagnosed CSP cases. Undiagnosed CSP cases had higher rates of anemia, longer hospital stays, and higher cost than diagnosed CSP cases (Table 3). Eleven undiagnosed CSP cases developed serious complications such as placenta accreta, placenta previa, uterine rupture, heavy bleeding during surgery, or were given a diagnosis of "near miss" (Table 3).

\section{Actual diagnosis for undiagnosed CSP cases at the first contact with healthcare providers}

Table 4 displays the diagnosis of cases that initially failed to be recognized as CSP. Most of these cases were initially diagnosed as normal early pregnancy followed by abortions (Table 4).

\section{Discussion}

\section{Main findings}

Our study found that a large proportion of CSP cases (41.5\%) were undiagnosed as CSP but were diagnosed as normal pregnancies or abortions at the first contact with healthcare providers. The only significant risk factor for undiagnosed CSP was the first point of care at a primary or secondary level hospital. Undiagnosed cases had higher rates of serious complications and post-surgery anemia, stayed longer in hospital, and had higher cost than diagnosed cases.

\section{Strengths and limitations}

To our knowledge, this is the first study that explored risk factors of undiagnosed CSP at the first contact of healthcare providers and compared outcomes between undiagnosed CSP cases and diagnosed CSP cases [1, 5, 6, 8-21]. The study population included all CSP cases who were treated in the catchment area, therefore, there was no selection bias. This study is also one of the largest in the field $[1,5,6,8-21]$. The final diagnosis of CSP was valid and solid, and the chance of misclassification at the final diagnosis was unlikely. We analyzed risk factors for undiagnosed CSP cases from both the patient and healthcare provider perspective, which helps to interpret the results and compare with previous studies.

The maternity care team of the only tertiary maternity care hospital in Qingyuan region is experienced in treating high-risk pregnancies, which ensured that no death occurred in the CSP cases during the study period. However, serious complications such as placenta accreta, placenta previa, uterine rupture, and heavy bleeding did 
Table 2 Risk factors of undiagnosed CSP at the first contact of healthcare providers, Qingyuan, Guangdong, China, 2013 to 2017

\begin{tabular}{|c|c|c|c|c|}
\hline Determinants & $\begin{array}{l}\text { Number of } \\
\text { undiagnosed CSP }\end{array}$ & $\begin{array}{l}\text { Rate of undiagnosed } \\
\text { CSP (\%) }\end{array}$ & $\begin{array}{l}\text { Crude RR } \\
(95 \% \mathrm{Cl}) \\
\end{array}$ & $\begin{array}{l}\text { Adjusted RR } \\
(95 \% \mathrm{Cl})\end{array}$ \\
\hline \multicolumn{5}{|l|}{ Age } \\
\hline$<30(n=68)$ & 31 & 45.59 & Reference & Reference \\
\hline$>30(n=127)$ & 50 & 39.37 & $0.86(0.62,1.21)$ & $1.02(0.64,1.64)$ \\
\hline \multicolumn{5}{|l|}{ Parity } \\
\hline $1(n=106)$ & 45 & 42.45 & Reference & Reference \\
\hline$>=2(n=89)$ & 36 & 40.45 & $0.96(0.7,1.31)$ & $0.87(0.70,1.09)$ \\
\hline \multicolumn{5}{|l|}{ Rural residence } \\
\hline Yes $(n=120)$ & 50 & 41.33 & $1.01(0.8,1.26)$ & $0.97(0.73,1.29)$ \\
\hline No $(n=75)$ & 31 & 41.33 & Reference & Reference \\
\hline \multicolumn{5}{|c|}{ Gestational age in week at initial contact with healthcare providers } \\
\hline$<6$ weeks $(n=41)$ & 12 & 29.27 & Reference & Reference \\
\hline $6-7$ weeks $(n=92)$ & 33 & 35.87 & $1.09(0.87,1.38)$ & $1.26(0.86,1.85)$ \\
\hline$>=7$ weeks $(n=62)$ & 36 & 58.06 & $1.59(1.15,2.19)$ & $1.82(0.98,3.37)$ \\
\hline \multicolumn{5}{|c|}{ Type of initial health care facilities } \\
\hline Primary $(n=56)$ & 41 & 73.21 & $3.81(2.35,6.16)$ & $3.28(2.06,5.22)$ \\
\hline Secondary $(n=61)$ & 25 & 40.98 & $1.72(1.21,2.45)$ & $1.91(1.16,3.13)$ \\
\hline Tertiary $(n=78)$ & 15 & 19.23 & Reference & Reference \\
\hline
\end{tabular}

occur in CSP cases who were undiagnosed at the first contact with healthcare providers, and two such cases were in "near miss".

We used post-surgical anemia to serve as an indicator of the severity and complexity of the patient's condition. Data on laboratory-diagnosed anemia from medical charts are reliable. In this study, more than $28 \%$ of women with undiagnosed CSP developed post-surgical anemia, while only 7\% with diagnosed CSP. Moreover, undiagnosed CSP cases had longer hospital stays and higher cost than diagnosed cases, indicating that undiagnosed CSP not only affects the patient's health, but also imposes a burden on the health care system. However, sample size of this study may be limited to assess smaller effects. Some factors such as gestational age at the first contact with healthcare providers may become significant if a larger study sample is available. The data did not have information on previous pregnancies such as quality and healing process of previous cesarean section, which prevented us from in-depth investigation of the causes for failure to a timely diagnosis of CSP.

\section{Interpretation}

The rate of CSP in this study was in the high end among previous studies [4-6]. This is not a surprise given the historically high cesarean section rate [2] and the recent change in second-child policy in China [7]. Most previous studies in this field described clinical features of CSP cases only $[1,5,6,8-21]$, with no attempt to examine risk factors for undiagnosed CSP at initial contact with healthcare providers. Risk of CSP appears to be increased with the number of cesareans, history of dilatation and curettage, placental pathology, history of ectopic pregnancy, and use of assisted reproductive

Table 3 Comparison of outcomes between undiagnosed and diagnosed CSP at the first contact with healthcare providers, Qingyuan, Guangdong, China, 2013 to $2017^{a}$

\begin{tabular}{llll}
\hline Outcomes & $\begin{array}{l}\text { Undiagnosed } \\
(N=81)\end{array}$ & $\begin{array}{l}\text { Diagnosed } \\
(N=114)\end{array}$ & $<$ Value \\
\hline Serious complications $(\mathrm{n}, \%)^{\mathrm{a}}$ & $11(13.6)$ & $0(0.0)$ & $<.001$ \\
Anemia (n, \%) & $23(28.4)$ & $8(7.0)$ & $<.01$ \\
Length of hospital stay (in days; Mean, SD) $^{\mathrm{c}}$ & $5.5 \pm 3.2$ & $4.6 \pm 2.0$ & 0.03 \\
Hospital cost (in RMB Yuan; Mean, SD) $^{\mathrm{d}}$ & $8626.2 \pm 5995.1$ & $6199.0 \pm 3859.7$ & $<0.01$ \\
\hline
\end{tabular}

${ }^{a}$ Occurrence of any of the following condition: placenta accrete, placenta previa, uterine rupture, heavy bleeding, and near miss; difference between the two groups was compared by Fisher exact test

${ }^{\mathrm{b}}$ Difference between the two groups was compared by chi-square test

'Difference between the two groups was compared by t-test

dOne US dollar was about 6.5 RMB during the study period; Difference between the two groups was compared by t-test 
Table 4 Initial diagnosis of undiagnosed CSP cases at the first contact of healthcare providers, Qingyuan, Guangdong, China, 2013 to 2017

\begin{tabular}{lll}
\hline Initial diagnosis & $\begin{array}{l}\text { Number of undiagnosed } \\
\text { cases }(N=81)\end{array}$ & $\begin{array}{l}\text { As a percent of all } \\
\text { undiagnosed cases (\%) }\end{array}$ \\
\hline $\begin{array}{l}\text { Normal early } \\
\text { pregnancy }\end{array}$ & 40 & 49.4 \\
Abortions & 27 & 33.3 \\
$\begin{array}{l}\text { Other ectopic } \\
\text { pregnancy }\end{array}$ & 3 & 3.7 \\
Others & 11 & 13.6 \\
\hline
\end{tabular}

technology such as IVF [4]. Although the importance of timely diagnosis for CSP has been discussed in these studies $[1,5,6,8-21]$, risk factors for failure to make a timely diagnosis have not been assessed.

Risk factors for CSP are different from risk factors for undiagnosed CSP. Our study suggests that for diagnosis, risk factors from healthcare providers may be more important than those from patients, because patient's characteristics (e.g. age, parity, rural residence, and gestational age) were not statistically significantly associated with diagnosis, while the level of health care facility was. We should emphasize that, in this study, undiagnosed CSP refers to the diagnosis at patient's first contact with a healthcare provider - eventually all CSP cases were diagnosed accurately. Delaying in diagnosis contributes greatly to adverse outcomes. If a diagnosis of normal pregnancy is made at the initial visit, pregnancy may continue and lead to serious conditions such as placenta accreta or placenta previa. As in other aspects of health care and in other parts of China [23, 24], huge variations in terms of competence of health care providers and facilities in maternity care exist in Qingyuan. Primary care is mostly provided by township hospitals and secondary care is mostly provided by county hospitals. In these primary and secondary care facilities, medical workers, including both sonographers and physicians, often lack relevant CSP knowledge to make an accurate diagnosis [25]. Furthermore, these hospitals have no vaginal ultrasound or color Doppler and only have abdominal ultrasound. Abdominal assessment lacks resolution, particularly in early pregnancy and may not have an accurate diagnosis. It is, therefore, crucial to ensure that medical staff at these hospitals take carefully medical histories including cesarean section and vaginal bleeding and transfer patients with a suspected CSP to tertiary care centers for further assessment.

We searched Medline with key words of "Cesarean Scar Pregnancy AND Diagnosis", and identified one case report that described a CSP that was initially diagnosed as another condition despite using ultrasound [21]. This report emphasizes the need for formal training of staff in all maternal care centers. Transvaginal ultrasound examination has advantages of being easy to operate, repeatable, and low cost, and should be the first choice. Diagnosis of CSP by vaginal ultrasonographic examination could be established as follows: 1) uterus is slightly enlarged, 2) there is no pregnancy in uterine cavity, 3) endometrial line is clearly visible, 4) a gestational sac with a york sac or crown length with or without heart rate, or complex mass with mixed echogenicity is located in the myometrium at the level of lower uterine segment, and is surrounded by visible blood flow, and 5) muscular layer between gestational sac and bladder is thin $[3-6,26-30]$. Any pregnant woman with a history of cesarean section should be evaluated for CSP, using a thorough ultrasound assessment. For pregnant women with a history of cesarean section and vaginal bleeding, blind suction or curettage is dangerous.

\section{Conclusions}

Initial care provided at primary or secondary maternity care facilities is an important risk factor for undiagnosed CSP, with serious consequences to the affected women.

High degree of awareness, detailed history, skillful ultrasound examination, and timely referral of suspected CSP patients to a tertiary care center are keys for accurate diagnosis.

\section{Abbreviations \\ Cl: Confidence interval; CSP: Cesarean scar pregnancy; HCG: Human chorionic gonadotropin; IVF: In vitro fertilization; MRI: Magnetic resonance imaging; RR: Relative risk}

\section{Acknowledgements}

We thank participants and physicians/nurses at the maternity care team of The Sixth Affiliated Hospital of Guangzhou Medical University for their support.

\section{Authors' contributions}

SWW, HZL, and RHX designed the study and drafted the manuscript. XYG, $M L, L G$ and $M W$ substantively revised the manuscript and made substantial contribution to the interpretation of the data. YL with assistance from SWW and RHX performed statistical analysis. All authors have approved the submitted version, have agreed both to be personally accountable for the author's own contributions and to ensure that questions related to the accuracy or integrity of any part of the work, even ones in which the author was not personally involved, are appropriately investigated, resolved, and the resolution documented in the literature. HZL and SWW are the guarantors. The correspondence authors attest that all listed authors meet authorship criteria.

\section{Funding}

This study was supported in part by grants from Canadian Institute of Health Research (FND-148438), Southern Medical University (LC2019ZD019), and Nanhai Hospital of Southern Medical University (YNKT201802). Funders did not play any role in the design of the study, the collection, analysis, and interpretation of data and in writing the manuscript.

\section{Availability of data and materials}

The data of this study are stored in secured servers of the institutions and are available from the corresponding authors on reasonable request.

Ethics approval and consent to participate

This cohort study used data collected for routine quality assurance purposes, thus the Research Ethics Board of The Sixth Affiliated Hospital of Guangzhou 
Medical University concluded that an ethical approval was not required and consent from patients was not required.

\section{Consent for publication}

Not applicable.

\section{Competing interests}

The authors declare that they have no competing interests.

\section{Author details}

'Department of Nursing, General Practice Center, Nanhai Hospital, Southern Medical University, Foshan, Guangdong, China. ${ }^{2}$ Department of Obstetrics and Gynecology, the Sixth Affiliated Hospital of Guangzhou Medical University, Qingyuan, Guangdong, China. ${ }^{3}$ Department of Obstetrics, Nanhai Hospital, Southern Medical University, Foshan, Guangdong, China. ${ }^{4}$ Ottawa Hospital Research Institute, Ottawa, ON, Canada. ${ }^{5} \mathrm{OMNI}$ Research Group, Department of Obstetrics and Gynecology, University of Ottawa, 501 Smyth Road, Box 241, Ottawa, ON K1H 8L6, Canada. ${ }^{6}$ BORN (Better Outcome Registry Network) Ontario, Children's Hospital of Eastern Ontario, Ottawa, ON, Canada. ${ }^{7}$ School of Epidemiology and Public Health, University of Ottawa Faculty of Medicine, Ottawa, ON, Canada.

Received: 15 April 2019 Accepted: 20 September 2019

Published online: 26 October 2019

\section{References}

1. Timor-Tritsch IE, Monteagudo A, Santos R, Tsymbal T, Pineda G, Arslan AA. The diagnosis, treatment, and follow-up of cesarean scar pregnancy. Am J Obstet Gynecol. 2012;207:44.e1-13.

2. Timor-Tritsch IE, Monteagudo A. Unforeseen consequences of the increasing rate of cesarean deliveries: early placenta accrete and cesarean scar pregnancy. A review. Am J Obstet Gynecol. 2012;207:44.e14-29.

3. Timor-Tritsch IE, Monteagudo A, Cali G, Refaey HE, Agten AK, Arslan AA. Easy sonographic differential diagnosis between intrauterine pregnancy and cesarean delivery scar pregnancy in the early first trimester. Am J Obstet Gynecol. 2016;215:225.e1-7.

4. Riaz RM, Williams TR, Craig BM, Myers DT. Cesarean scar ectopic pregnancy: imaging features, current treatment oplions, and clinical autcomes. Abdom Imaging. 2015:40:2589-99.

5. Maymon R, Halperin R, Mendlovic S, Schneider D, Herman A. Ectopic pregnancies in a caesarean scar: review of the medical approach to an iatrogenic complication. Hum Reprod Update. 2004;10:512-23.

6. Harb HM, Knight M, Bottomley C, Overton C, Tobias A, Gallos ID, et al. Caesarean scar pregnancy in the UK: a national cohort study. BJOG. 2018. https://doi.org/10.1111/1471-0528.15255

7. Liang J, Mu Y, Li X, Tang W, Wang Y, Liu Z, et al. Relaxation of the one child policy and trends in caesarean section rates and birth outcomes in China between 2012 and 2016: observational study of nearly seven million health facility births. BMJ. 2018;360:k817.

8. Ghezzi F, Laganà D, Franchi M, Fugazzola C, Bolis P. Conservative treatment by chemotherapy and uterine arteries embolization of a cesarean scar pregnancy. Eur J Obstet Gynecol Reprod Biol. 2002;103:88-91.

9. Fylstra DL, Pound-Chang T, Miller MG, Cooper A, Miller KM. Ectopic pregnancy within a cesarean delivery scar: a case report. Am J Obstet Gynecol. 2002;187:302-4.

10. Lam PM, Lo KW. Multiple-dose methotrexate for pregnancy in a cesarean section scar. A case report. J Reprod Med. 2002:47:332-4.

11. Haimov-Kochman R, Sciaky-Tamir Y, Yanai N, Yagel S. Conservative management of two ectopic pregnancies implanted in previous uterine scars. Ultrasound Obstet Gynecol. 2002;19:616-9.

12. Hartung J, Meckies J. Management of a case of uterine scar pregnancy by transabdominal potassium chloride injection. Ultrasound Obstet Gynecol. 2003:21:94-5.

13. Chuang J, Seow KM, Cheng WC, Tsai YL, Hwang JL. Conservative treatment of ectopic pregnancy in a caesarean section scar. Br J Obstet Gynecol. 2003; 110:869-70.

14. Yang MJ, Jeng MH. Combination of transarterial embolization of uterine arteries and conservative surgical treatment for pregnancy in a cesarean section scar. J Reprod Med. 2003;48:213-6.

15. Weimin W, Wenqing L. Effect of early pregnancy on a previous lower segment cesarean section scar. Int J Gynaecol Obstet. 2002;77:201-7.
16. Jurkovic D, Hillaby K, Woelfer B, Lawrence A, Salim R, Elson CJ. First-trimester diagnosis and management of pregnancies implanted into the lower uterine segment cesarean section scar. Ultrasound Obstet Gynecol. 2003;21:220-7.

17. Maymon R, Halperin R, Mendlovic S, Schneider D, Vaknin Z, Herman A, et al. Ectopic pregnancies in cesarean section scars: the 8-year experience of one medical center. Hum Reprod. 2004;19:278-84.

18. Seow KM, Huang LW, Lin YH, Lin MY, Tsai YL, Hwang JL. Cesarean scar pregnancy: issues in management. Ultrasound Obstet Gynecol. 2004;23:247-53.

19. Shih JC. Cesarean scar pregnancy: diagnosis with three-dimensional (3D) ultrasound and 3D power Doppler ultrasound. Obstet Gynecol. 2004;23:306-7.

20. Marchiolé P, Gorlero F, de Caro G, Podestà M, Valenzano M. Intramural pregnancy embedded in a previous cesarean section scar treated conservatively. Ultrasound Obstet Gynecol. 2004;23:307-9.

21. Einenkel J, Stumpp P, Kösling S, Horn LC, Höckel M. A misdiagnosed case of caesarean scar pregnancy. Arch Gynecol Obstet. 2005;271:178-81.

22. Qingyuan Bureau of Statistics. Qingyuan 2017 Statistics. Guangdong: Qingyuan, 2017

23. Wong WCW, Zhu S, Ong JJ, Peng M, Lam CLK, Kidd MR, Roland M, Jiang S. Primary care workforce and continuous medical education in China: lessons to learn from a nationwide cross-sectional survey. BMJ Open. 2017;7: e015145.

24. Wang $X$, Jiang $R$, Li J, Chen J, Burström B, Burström K. What do patients care most about in China's public hospitals? Interviews with patients in Jiangsu Province. BMC Health Serv Res. 2018;18:97.

25. Zhang $A, X u Y$. Discussion of the misdiagnosed reasons of uterine scar pregnancy after cesarean section. Modern Med J. 2012:8:447-8.

26. Oshorn D, Williams TR, Graing BM. Cesarean scar pregnancy: sonographic andmagnetic resonance imaging finds, complications, and treatment. J Ultrasound Med. 2012;3:1449-56

27. Armstrong V, Hansen WF, Van Voorhis BJ, Syrop CH. Detection of cesarean scars by transvaginal ultrasound. Obstet Gynecol. 2003;101:61-5.

28. Cheng PJ, Chueh HY, Soong YK. Sonographic diagnosis of a uterine defect in a pregnancy at 6 weeks' gestation with a history of curettage. Ultrasound Obstet Gynecol. 2003;21:501-3.

29. Lin M, Xie H, Zh Y. Application of ultrasound in surveillance of cearean section scar pregnancy and cervical pregnancy. Chin Med Imaging. 2006; 175:266-8.

30. Pędraszewski P, Wlaźlak E, Panek W, Surkont G. Cesarean scar pregnancy - a new challenge for obstetricians. J Ultrason. 2018;18:56-62.

\section{Publisher's Note}

Springer Nature remains neutral with regard to jurisdictional claims in published maps and institutional affiliations.

Ready to submit your research? Choose BMC and benefit from:

- fast, convenient online submission

- thorough peer review by experienced researchers in your field

- rapid publication on acceptance

- support for research data, including large and complex data types

- gold Open Access which fosters wider collaboration and increased citations

- maximum visibility for your research: over $100 \mathrm{M}$ website views per year

At BMC, research is always in progress.

Learn more biomedcentral.com/submissions 